\title{
Perancangan dan Implementasi Sistem Informasi Lokasi Dojang Taekwondo Berbasis Web
}

\author{
Jenih Jenih, Moh Ariansyah A Ointu, Tony Sugiarso \\ Universitas Respati Indonesia \\ jenih@fti.urindo.ac.id, ariointu@gmail.com, tony.sugiarso@urindo.ac.id
}

\begin{abstract}
ABSTRAK
DKI Jakarta merupakan salah satu Provinsi yang memiliki cukup banyak anggota taekwondo di Indonesia, Kec.Cipayung adalah salah satu kecamatan yang ada di Jakarta timur yang memiliki antusias masyarakat cukup tinggi terhadap bela diri Taekwondo, dibuktikan dengan banyaknya Dojang (tempat berlatih taekwondo) yang didirikan di wilayah Jakarta Timur, namun permasalahan yang ditemukan yaitu tentang sumber informasi lokasi dojang yang di sediakan hanya berupa kordinat lokasi, sedangkan untuk informasi terkait hal-hal portofolio pelatih, status tingkatan $D A N$, tahun berdiri, informasi kontak, serta regional kota belum lengkap. Pendekatan penelitian pembuatan aplikasi sistem informasi lokasi dojang taekwondo dengan menggunakan System Development Life Cycle (SDLC), yaitu merupakan metode yang digunakan untuk melakukan pengembangan perangkat lunak. Adapun metodologi yang digunakan yaitu struktur desain berupa waterfall. Manfaat dari aplikasi ini adalah membantu para taekwodoin dalam memperoleh informasi tentang tempat latihan (Dojang). Selain itu, aplikasi ini juga dapat bermanfaat untuk umum mengenai taekwondo.
\end{abstract}

Kata kunci : taekwondo, portofolio,pelatihan.

\begin{abstract}
DKI Jakarta is one of the provinces which has quite a lot of taekwondo members in Indonesia, Cipayung Subdistrict is one of the districts in east Jakarta that has quite a high level of community enthusiasm for Taekwondo martial arts, as evidenced by the large number of Dojang (taekwondo practice areas) established in East Jakarta region, but the problems found were about the source of location information provided only in the form of location coordinates, whereas for information related to trainer portfolio matters, status of the AND level, standing year, contact information, and the city area was incomplete. The research approach makes the application of the taekwondo location information system using the System Development Life Cycle (SDLC), which is a method used to conduct software development. The methodology used is the design structure in the form of a waterfall. The benefit of this application is to help the taekwodoin in obtaining information about the training ground (Dojang). In addition, this application can also be useful to the public regarding taekwondo.
\end{abstract}

Keywords: taekwondo, portfolio, training. 


\section{PENDAHULUAN}

Taekwondo adalah seni beladiri yang lebih menekankan pada penggunaan kaki dan tangan. sebab secara etimologi Taekwondo terdiri dari 3 kata dasar yaitu Tae yang berarti kaki, Kwon yang berarti tangan serta Do yang beraarti seni. Menurut sejarah beladiri ini berkembang sejak tahun $37 \mathrm{M}$ di negara Korea. Di Indonesia sendiri untuk organisasi yang mengurusi bela diri Taekwondo adalah Pengurus Besar Taekwondo Indonesia (PBTI). kini organisasi tersebut telah memiliki koordinator di setiap provinsi. Berbanding terbalik dengan antusias masyarakat yang cukup tinggi untuk mengikuti pelatihan taekwondo, banyak juga yang kesulitan untuk mencari informasi tentang tempat berlatih (Dojang). Untuk mencari informasi tempat pelatihan taekwondo memang cukup mudah namun informasi yang disediakan hanya berupa titik koordinat lokasi saja. Sedangkan untuk informasi yang lebih lengkap untuk menandakan bahwa dojang tersebut merupakan tempat berlatih taekwondo yang memenuhi kriteria lengkap belum ada. Sehingga dibuatlah sebuah sistem informasi lokasi dojang yang mudah diakses oleh masyarakat

\section{METODE}

Pendekatan penelitian pembuatan aplikasi sistem informasi lokasi dojang taekwondo dengan menggunakan System Development Life Cycle (SDLC), yaitu merupakan metode yang digunakan untuk melakukan pengembangan perangkat lunak. Adapun metodologi yang digunakan yaitu struktur desain berupa waterfall.

Metodelogi Structured Design merupakan pendekatan yang digunakan dalam pengembangan sistem, mengikuti tahapan siklus hidup sistem dan dibekali alat-alat dan teknik-teknik yang memadai. Metodologi yang menggunakan Structured Desing meliputi metode Waterfall, metodologi dengan sekuensi linear terdiri dari tahapan perencanaan sistem (rekayasa sistem), analisis kebutuhan, desain, penulisan program, pegujian dan perawatan sistem. Berikut adalah bagian dari waterfall model seperti pada gambar 1 metode waterfall.

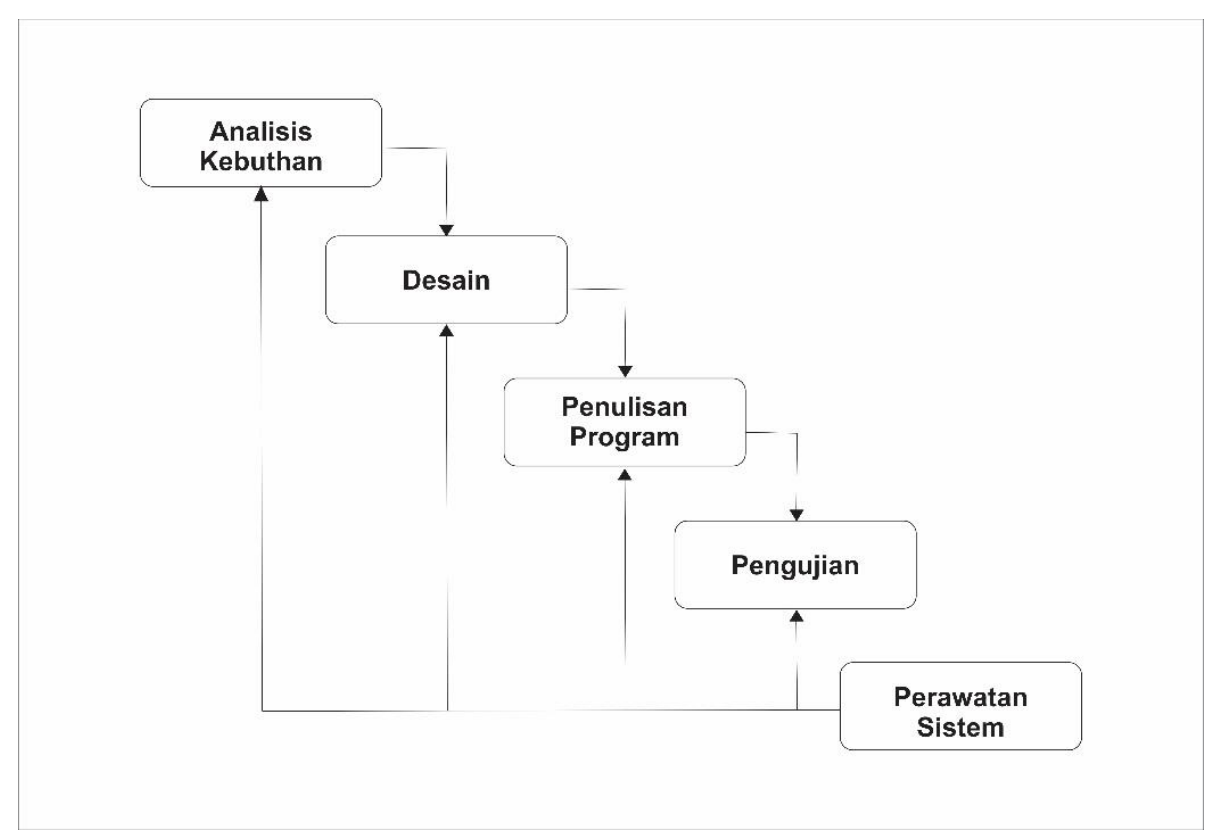




\section{Gambar 1 Metode Waterfall}

Berikut ini merupakan deskripsi dari tahapan-tahapan yang dilakukan peneliti dalam pembuatan aplikasi "SI DOJANG", yaitu:

1. Analisis sistem yaitu merencanakan bagaimana aplikasi akan dibuat, perangkat lunak dan perangkat keras apa saja yang dibutuhkan untuk bisa membuat aplikasi "SI DOJANG".

2. Desain sistem adalah merancang atau mendesain aplikasi "SI DOJANG" dengan desain yang mudah digunakan dan juga memiliki tampilan interface yang menarik, serta merancang pemodelan aplikasi yang digunakan seperti use case diagram, sequence diagram, class diagram dan diagram activity.

3. Penulisan program adalah tahap kode perancangan aplikasi ini secara keseluruhan yang meliputi proses pengetikan kode program (coding).

4. Pengujian aplikasi yang telah jadi harus diuji coba setiap fungsi-fungsinya agar dapat diketahui permasalahanya dan juga sesuai dengan kebutuhan yang diperlukan.

5. Perawatan adalah tahap terakhir dari metode waterfall. Perawatan bertujuan untuk mengubah atau menambahkan fungsi yang diinginkan oleh pengguna serta ketika ditemukannya kesalahan.

\section{Alur Program Aplikasi Dojang}

Alur program aplikasi dojang merupakan penjelasan secara logika tentang langkah-langkah atau algoritma dari aplikai yang dirancang, Alur program aplikasi dojang digambarkan dengan Use Case Diagram, Activity Diagram, dan Sequence Diagram.

\section{A. Use Case Diagram}

Use Case Diagram
mendeskripsikan sebuah
interaksi antara satu atau lebih
aktor dengan sistem informasi
yang akan dibuat, berikut Use
Case Diagram pada aplikasi
dojang seperti pada gambar 2.




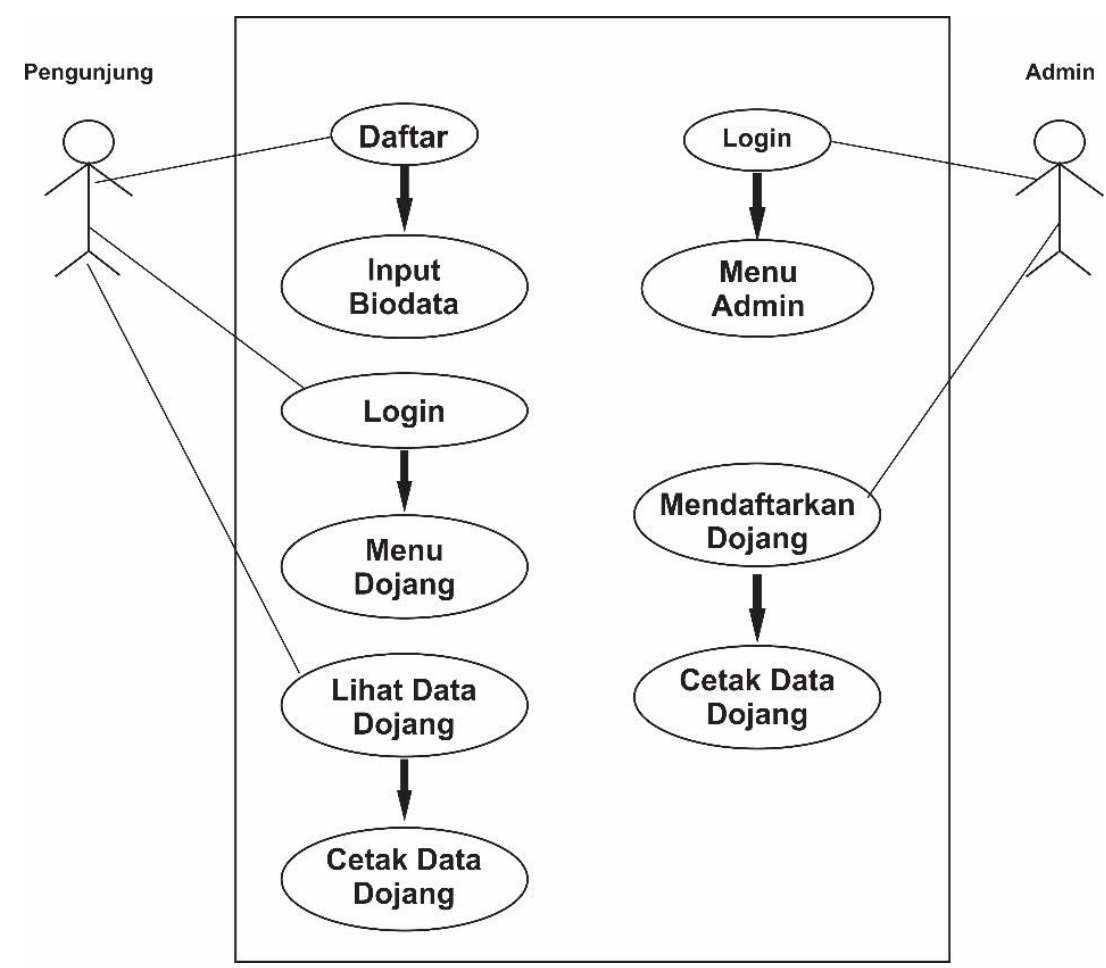

Gambar 2 Usecase Diagram

\section{B. Activity Diagram}

\begin{tabular}{lr}
\multicolumn{1}{c}{ Activity } & Diagram \\
menggambarkan logika \\
procedural, proses bisnis dan \\
aliran aktifitas dalam aplikasi \\
yang sedang dirancang, \\
Activity Diagram akan \\
menggambarkan proses \\
dimulai, decision yang akan \\
terjadi dan akhir aliran \\
aktifitas. \\
Activity Diagram \\
pengunjung \\
Proses activity diagram \\
pengunjung dimulai dari \\
pendaftaran akun user, \\
lalu pengunjung dapat \\
login setelah proses \\
pendaftaran akun \\
selesai $\quad$ dibuat. \\
Kemudian sistem akan
\end{tabular}

menampilkan menu pengunjung yang menyediakan informasi data dojang, pengunjung dapat memilih data dojang berdasarkan lokasi terdeka dengan cara memilih regional dojang pada kolom regional yang disediakan didalam aplikasi dojang, pengunjung pun dapat mencetak data dojang setelah memilih data dojang yang akan dicetak. Setelah kebutuhan informasi sudah didapatkan, pengunjung dapat logout dari aplikasi, seperti terlihat pada gambar 3 . 


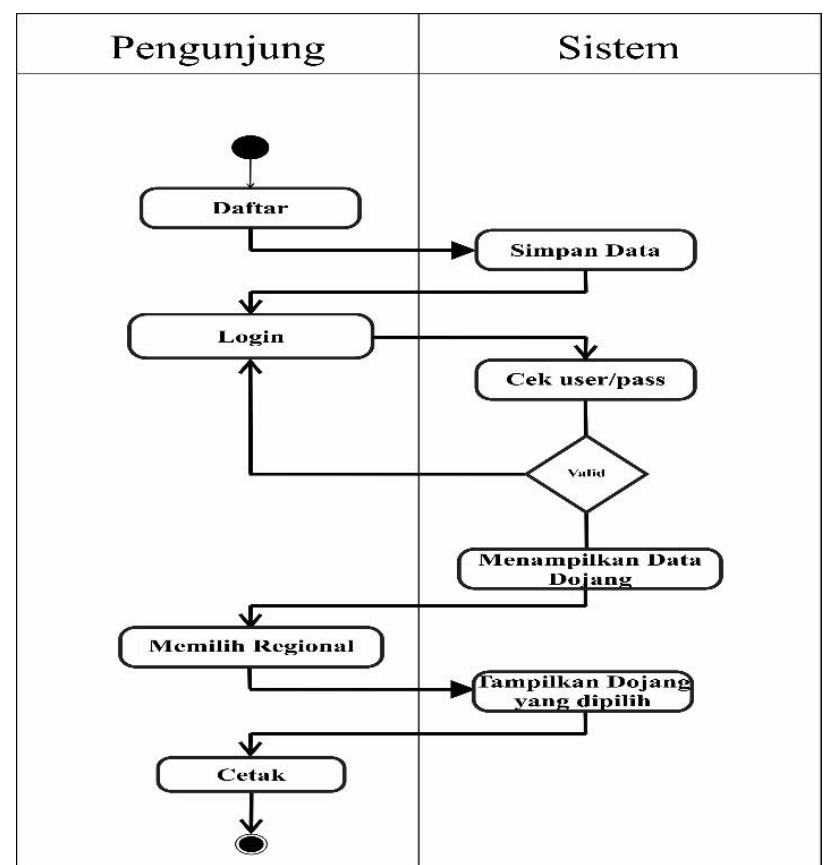

Gambar 3. Activity Diagram Pengunjung

\section{Sequence Diagram}

Diagram ini digunakan untuk menggambarkan prilaku pada sebuah skenario, menunjukan sebuah objek dari diagram sebelumnya, maka dapat dibuat diagram sequence seperti pada gamabar 4.

Sequence Diagram Pengunjung

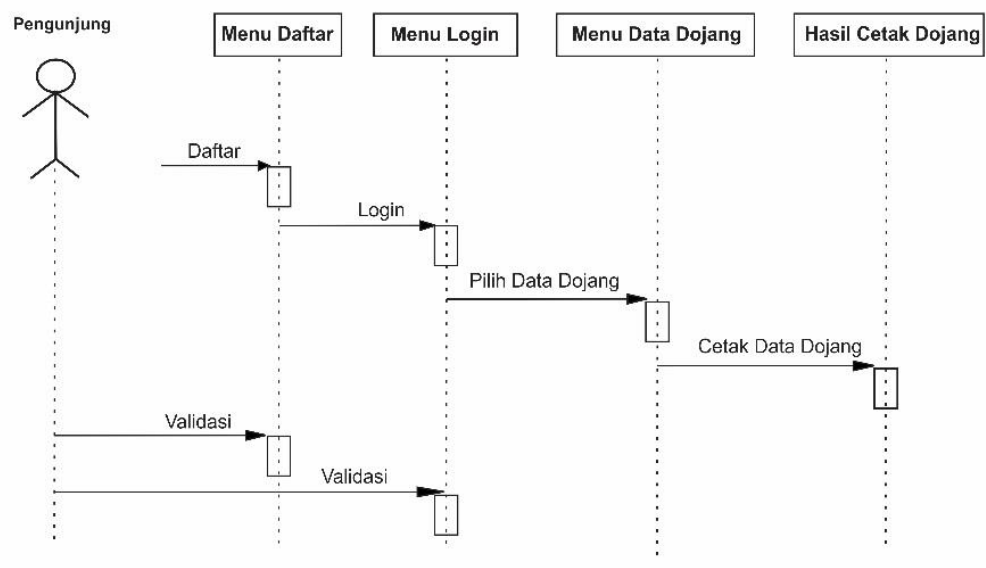

Gambar 4. Sequence Diagram Pengunjung 
HASIL

Berikut adalah tampilan sistem infromasi Dojang :

Halaman untuk daftar pengunjung baru. Pengunjung dapat melakukan registrasi untuk membuat akun personal yang baru dengan mengisikan form daftar baru pengunjung, komponen dari form diatas terdiri dari :Nama Awal, Nama Akhir, Email, Kata Sandi, Konfirmasi Kata Sandi dan Button Daftar, seperti pada gambar 5 .

Daftar Baru Pengunjung!

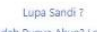

Gambar 5 Halaman Daftar Baru Pengunjung

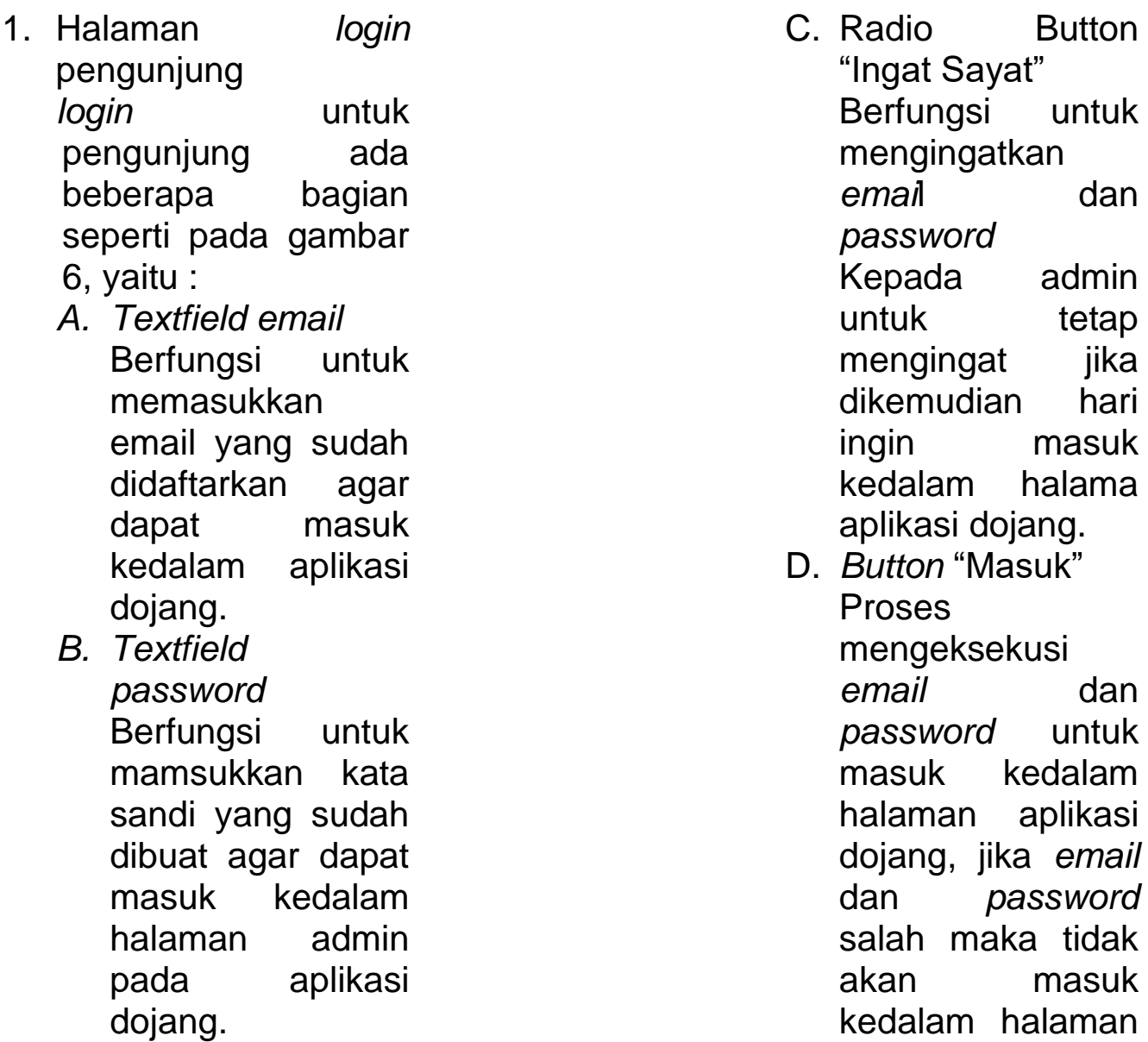




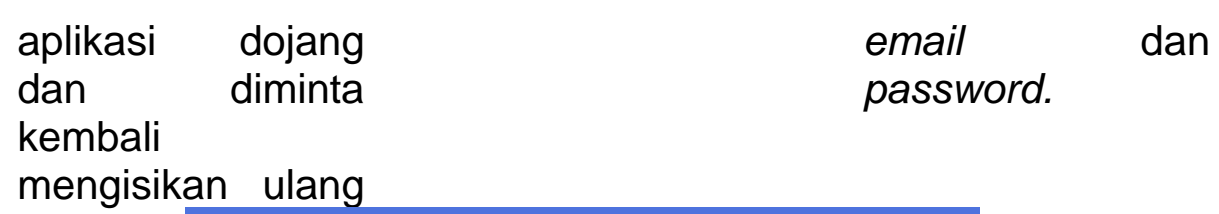

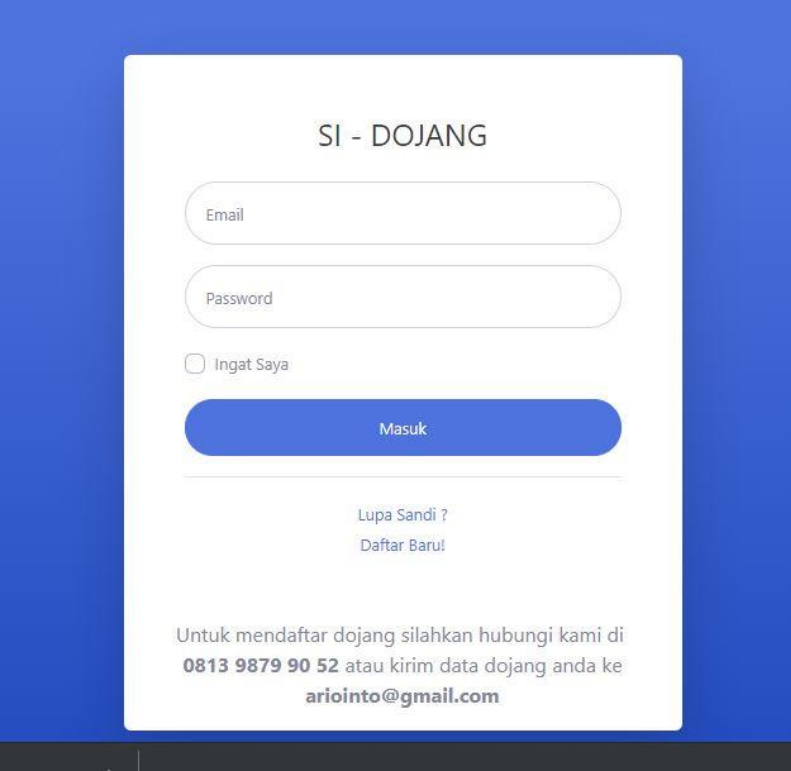

Gambar 6 Halaman Login Pengunjung

2. Rancangan halaman lihat data dojang berdasarkan regional Beberapa komponen yang terdapat dalam tampilam halaman utama, seperti pada gambar 7 yaitu :

A. Link "Master Data" Berfungsi untuk melihat beberapa menu yang ada di halaman apliaksi dojang seperti : Data Pengunjung, Data Dojang, dan Data admin.

B. Textfield "Pencarian" Berfungsi untuuk mencari data dojang yang sudah terdaftar dengan cara mengetik nama dojang didalam Texfieldnya.

C. Table Data Dojang

Data dojang ditampilkan pada table ini yang diurutkan sesuai nomer id-nya, Setiap nama dojang memiliki Link, jika diklik nama dojang maka akan muncul informasi dojang secara detil, dan dapat dicetak.

D. Button "Previuos dan Next" Berfungsi untuk melihat data dojang ke urutan sebelumnya dan data dojang selanjutnya. 


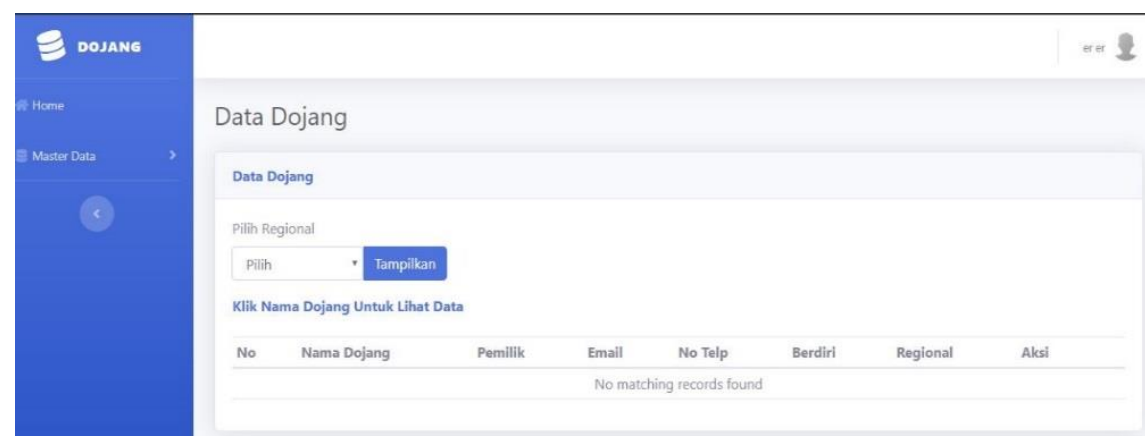

Gambar 7. Halaman Lihat Data Dojang

3. Rancangan halaman

berupa file.pdf dapat cetak data dojang

Hasil cetak data dojang seperti pada di-perint-out ke gambar diatas, dan printer, seperti pada gambar 8.
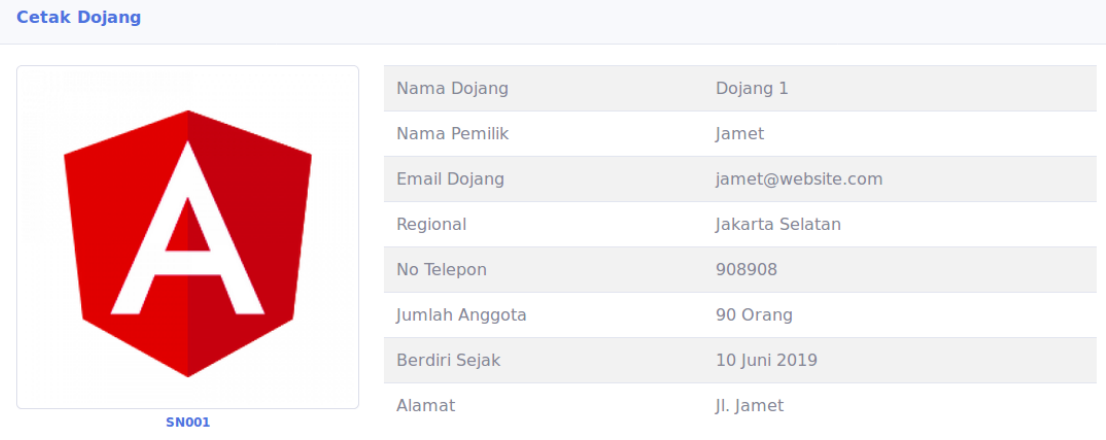

Gambar 8. Halaman Cetak Data Dojang

\section{SIMPULAN}

Berdasarkan pembahasan yang telah dilakukan terhadap aplikasi "Dojang berbasis web" maka dapat diambil kesimpulan sebagai beikut :

1. Memberikan kemudahan bagi masyarakat untuk mendapatkan informasi tentang dojang.

2. Memberikan kemudahan bagi masyarakat untuk mendaftar sebagai anggota dojang.

\section{DAFTAR PUSTAKA}

1. Al bahra bin ladjamudin, 2005. Analisis Sistem Informasi dan Desain Sistem Informasi. Graha ilmu,Yogyakarta
2. Budi raharjo, Imam heryanto, E.

Rosdiana K, 2014.

Pemprograman WEB

(HTML,PHP,MySQL). Modula, Bandung.

3. Hanif Alfatta, 2007. Analisis dan perancangan Sistem Informasi untuk Keunggulan Bersaing Perusahan dan Organisasi Modern. CV ANDI OFFSET ( penerbit andi ), Yogyakarta.

4. Prof. Dr. Jogiyanto HM, MBA, 2005. Analisis \& Desain Sistem Informasi pendekatan tekstruktur, CV ANDI OFFSET ( penerbit andi ), Yogyakarta. 
5. Kendall dan kendall, 2014. Analisis dan Perancangan Sistem, PT.Indeks Kelompok gramedia. Jakarta. 